\title{
CHEMICAL CHARACTERISTICS OF POND WATERS IN THE LABYRINTH OF SOUTHERN VICTORIA LAND, ANTARCTICA (ABSTRACT)
}

\author{
Tetsuya ToriI ${ }^{1}$, Shyu Nakaya ${ }^{2}$, Osamu Matsubaya ${ }^{3}$, Genki I. Matsumoto ${ }^{4}$, \\ Nobuki TAKamatsu ${ }^{5}$, Noriyasu MaSUdA ${ }^{6}$, Tamio KAWANO ${ }^{7}$ \\ and Haruta MURAYAMA ${ }^{8}$ \\ ${ }^{1}$ Chiba Institute of Technology, 17-1, Tsudanuma 2-chome, Narashino 275 \\ ${ }^{2}$ Department of Earth Sciences, Faculty of Science, Hirosaki University, \\ 3, Bunkyo-cho, Hirosaki 036 \\ ${ }^{3}$ Research Institute of Underground Resources, Mining College, Akita University, \\ 1-1, Tegatagakuen-cho, Akita 010 \\ ${ }^{4}$ Department of Chemistry, The College of Arts and Science, The University of Tokvo, \\ 8-1, Komaba 3-chome, Meguro-ku, Tokyo 153 \\ ${ }^{5}$ Department of Chemistry, Toho University, 2-1, Miyama 2-chon.e, Funabashi 275 \\ ${ }^{6}$ Department of Chemistry, Faculty of Fisheries, Hokkaido University, \\ 1-1, Minatomachi 3-chome, Hakodate 041 \\ ${ }^{7}$ Department of Chemistry, Faculty of Education, Oita University, \\ 700, Dannohara, Oita 870-11 \\ ${ }^{8}$ Department of Chemistry, Faculty of Education, Yokohama National University, \\ 156, Tokiwadai, Hodogaya-ku, Yokohama 240
}

\begin{abstract}
A large number of fresh and saline ponds are found in the Labyrinth $\left(77^{\circ} 33^{\prime} \mathrm{S}, 160^{\circ} 50^{\prime} \mathrm{E}\right)$ of the upper Wright Valley in the Dry Valleys region of southern Victoria Land, Antarctica. They are located near the terminus of the Wright Upper Glacier between $800-1000 \mathrm{~m}$ above sea level. From a limnological point of view, the most interesting problems concerning these saline ponds are the origin of their salts and their evolutional history.

Chloride ion contents vary remarkably among the ponds ranging from 0.0049 to $52.4 \mathrm{~g} \mathrm{~kg}^{-1}$. Surprisingly, more than a half of the ponds are saline with the highest chloride ion content being 2.7 times greater than that of seawater. The $\delta \mathrm{D}$ and $\delta^{18} \mathrm{O}$ values of the pond waters indicate a snow and/or glacier melt-water origin, and that the ponds underwent subsequent alteration due to evaporation or freezing. The composition of chemical components reveal no evidence of trapped seawater. Thus the salt concentrations in the Labyrinth pond waters must be explained principally by the accumulation of atmospheric salts and subsequent repeated cycles of evaporation and freezing of the pond waters over a considerable period of time. (This paper is submitted to the special issue of Hydrobiologia.)
\end{abstract}

(Received March 9, 1988) 